\title{
An Eco-Friendly Process for Removal of Lead from Aqueous Solution
}

\author{
Heman A. Smail ${ }^{1}$, Kafia M. Shareef ${ }^{2} \&$ Zainab H. Ramli ${ }^{3}$ \\ ${ }^{1}$ Department of Chemistry, College of Science, University of Salahaddin-Erbil, 44002 SUH Kirkuk Road, \\ Erbil-Iraq \\ ${ }^{2}$ Department of Clinical Biochemistry, College of Health Sciences, Erbil Medical University, Erbil- Iraq \\ ${ }^{3}$ Department of Chemistry, College of Science, UniversitiTechnologi Malaysia, 81310 UTM Skudai, Johor, \\ Malaysia \\ Correspondence: Heman Abdulqadr Smail, College of Science, University of Salahaddin-Erbil, 44002 SUH \\ Kirkuk Road, Erbil-Iraq. Tel: 964-750-455-3777. E-mail: heman.smail@su.edu.krd
}

Received: February 4, 2017

Accepted: February 25, 2017

Online Published: April 8, 2017

doi:10.5539/mas.v11n5p47

URL: https://doi.org/10.5539/mas.v11n5p47

\begin{abstract}
The adsorption of lead (Pb II) ion on different types of synthesized zeolite was investigated. The BET surface area, total pore volume \& average pore size distribution of these synthesized zeolites were determined by adsorption isotherms for $\mathrm{N} 2$, the surface area $\&$ total pore volume of their sources were found by adsorption isothermN2.The adsorption equilibrium was measured after $24 \mathrm{~h}$ at room temperature (RT) \& concentration $10 \mathrm{mg} . \mathrm{L}^{-1}$ of $\mathrm{Pb}$ (II) was used. The adsorption of heavy metal $\mathrm{Pb}$ (II) on four different prepared zeolites (LTA from Montmorillonite clay, FAU(Y)-B.H (G2) from Barley husk, Mordenite (G1) from Chert rock, FAU(X)-S.C (G3) from shale clay \& modified Shale clay by oxalic acid (N1) \& sodium hydroxide (N2)), were compared with the adsorption of their sources by using static batch experimental method. The major factors affecting the heavy metal ion sorption on different synthesized zeolites \& their sources were investigated. The adsorption equilibrium capacity (Qm) of $\mathrm{Pb}$ (II) ion for different synthesized zeolites ordered from $(\mathrm{N} 1>\mathrm{N} 2>\mathrm{LTA}>\mathrm{G} 3>\mathrm{G} 2>\mathrm{G} 1 \&$ for their sources ordered Shale clay $>$ Montmorilonite $>$ Barley husk $>$ Chert rock. The atomic absorption spectrometry was used for analysis of lead heavy metal ion, the obtained results in this study showed that the different synthesized zeolites were efficient ion exchanges for removing heavy metal, in particular, the modified zeolite from shale clay by oxalic acid.
\end{abstract}

Keywords: lead adsorption, zeolites, selectivity, isotherms

\section{Introduction}

Shale lithics might travel before they disintegrate, \& what their potential contribution to fine-grained successions in the rock record might be. Muds are common sediment on the earth surface $\&$ the precursors of fine grained clastic sedimentary rocks which are commonly known as shales or mudstones. Shales comprise approximately $2 / 3$ 's of the sedimentary rock record \& their constituents are derived from weathering \& erosion of the landmasses \& transported to the ocean basins by river systems that drain the continents (Potter et al., 2005). Barley husk is often considered as a solid waste from barley milling which contains highly pure silica $\left(\mathrm{SiO}_{2}\right)$ with \& an amorphous phase. Leaching of the barley husk with a mineral acid followed by calcination in air leads to produce a white powder of barley husk silica (BHS) (Katsuki et al., 2005). Zeolites can be defined as crystalline alumino silicate molecular sieves; variety of pore sizes \& topologies of zeolite can be synthesized. Zeolites are used as catalysts, adsorbents \& in chemical separation (Breck, 1974). As a result of larger accessible surface area $\&$ an easily mass transfer process of nanocrystals, zeolites can also be manipulated in establishing application such as sensing, medical diagnosing \& low-dielectric insulating (Li et al., 2005). Sources of water pollution of all kinds (industrial \& agricultural wastes, sewage, etc.) present a grave concern for public health. Toxic components including heavy metals are of special concern because of their potential for long-term accumulation in soil \& sediments. Unlike other pollutants, heavy metals are not biodegradable \& can accumulate in the environment $\&$ food chain, causing significant health risks. The high levels of exposure to heavy metals can cause cancer, organ damage, joint diseases, \& in extreme cases, death (Chary et al., 2008). Non-degradability of heavy metal ions and their persistence in the environment, leading to cause environmental problems. Therefore, the reduction of heavy metal ions from waste water is of great significance to save public health. 
There are many heavy metal sources, including metal plating, mining operations, burning of fossil fuels, fertilizer industry, \& textile industries, lead is one of the toxic metals \& one of the major environmental pollutants present in drinking water \& in air (Sitting, 1981). The main source of environmental lead pollution is the long use of leaded gasoline where higher concentrations of $\mathrm{Pb}$ (II) can still be found in soil \& plant matter along the roadside, even in countries, where leaded gasoline was replaced many years ago (Roulier et al., 2008).

\section{Experimental Sections}

\subsection{Material \& Instruments}

The analytical grades of reagents were used in this study. $\mathrm{Pb}\left(\mathrm{NO}_{3}\right)_{2}$ : VWR MERCK Chemicals Ltd Poole UK .The equipment used in the experimental setup were as follows: Centrifuge: Hermle Z200A south of Germany, shaking water bath Jeio Tech Co., Ltd BS-11 Gyeonggi-do Korea, Sieve: Aperture $500 \mu \mathrm{m}$ Stainless Steel UK. Atomic absorption: Thermo Electron Corporation:UK, BET-Micromeritics (3FLEX Surface characterization)

\subsection{Isotherm Adsorption}

After using the sieve $(500 \mu \mathrm{m})$ for all different type zeolite \& sources. Absorbent each Zeolite \&source $1.0 \mathrm{~g}$ was added to each test tube with $10 \mathrm{~mL}$ of the aqueous solution containing the concentration solutions of $\mathrm{Pb}$ (II) 10 mg. $\mathrm{L}^{-1}$. Mixtures were covered \& oscillated in a shaker at a constant speed of 150 round. $\mathrm{min}^{-1}$ at room temperature for 24 hour. The mixtures were then centrifuged at 3000 round. $\mathrm{min}^{-1}$ for $15 \mathrm{~min}$. The residual $\mathrm{Pb}$ (II) concentration in the solution was then determined using atomic absorption spectrometer.

The equilibrium adsorption capacity was calculated using the following equation (Soliman et al., 2016).

$$
\mathrm{Qm}=\frac{\mathrm{C}_{\mathrm{o}}-\mathrm{Ce}}{\mathrm{W}} \mathrm{X}
$$

where $\mathrm{Qm}$ is the equilibrium adsorption capacity $\left(\mathrm{mg} \cdot \mathrm{g}^{-1}\right)$, Co is the initial of $\mathrm{Pb}(\mathrm{II})$ concentration $\left(\mathrm{mg} \cdot \mathrm{L}^{-1}\right)$, Ce is the final $\mathrm{Pb}(\mathrm{II})$ concentration (mg. $\left.\mathrm{L}^{-1}\right)$, W is the weight of adsorbent used $(\mathrm{g}) \& \mathrm{~V}$ is the volume of $\mathrm{Pb}(\mathrm{II})$ solution $(\mathrm{mL}), \&$ the percentage adsorption $(\%)$ was calculated(ca.) as follows

$$
\% \text { Adsorption }=\frac{\mathrm{C}_{\mathrm{o}}-\mathrm{Ce}}{\mathrm{C}_{\mathrm{o}}} \mathrm{X} 100 \%
$$

The experiments were performed in triplicates to obtain average results. The BET surface area, Total pore volume \& pore size distribution of different type of zeolite were determined by BET analysis using Micromeritics 3 FLEX analyzer (Fujiwara et al., 2011). 0.2-0.3g of the sample was weighed \& heated at $350^{\circ} \mathrm{C}$, ramp rate $10^{\circ} \mathrm{C} / \mathrm{min}$ for $240 \mathrm{~min}$ to dehydrate the sample. The sample was removed quickly to the sample station to the nitrogen adsorption analysis where the analysis was fully done automatically by the instrument (Jaenicke et al., 2000). The BET surface area. Total pore volumes \& average pore size are important properties in zeolite catalysts. Nitrogen adsorption measurement is the technique used to measure these properties. This technique provides information on the BET surface area, total pore volumes \& average pore size (Gregg \& Sing, 1982).

\section{Result \& Discussion}

The results of the influence of $(\mathrm{Qm})$ are shown in Table 1, adsorption of the $\mathrm{Pb}$ (II) on the different type of sources \& synthesized zeolites. The amount of Qm steadily increases with increasing Brunauer, Emmet \& Teller (BET) surface area from chert rock, barley husk, Montmorillonite \& shale clay respectively from sources, also all sources have small surface area if compared to the zeolites this is due to lack of flat profile which observed in all sources, indicating that multilayer coverage of the sources. It is likely that adsorption sites took up the available metal ions more slowly at this concentration due to less active sites than adsorbate. Similar observations have been reported by (Olaofe et al., 2015) respectively. On the hand the amount of Qm increase with increasing BET surface area $(\mathrm{N} 1>\mathrm{N} 2>\mathrm{LTA}>\mathrm{G} 3>\mathrm{G} 2>\mathrm{G} 1$. This is because the BET surface area is very important parameters for the adsorption amount of $\mathrm{Pb}$ (II). The results of this study were in good agreements with results obtained from the literature (Megat et al., 2007). Also Table 1 indicates the percentage adsorption of $\mathrm{Pb}$ (II) using the studied zeolite samples. At this concentration of Pb (II) N1 \& N2, LTA, G3, G2 \& G1 showed to remove $97.73,96.85,95.09,94.16,93.12 \& 90.87 \%$ of $\mathrm{Pb}$ (II) respectively from the solution. Due to that, these samples can be used to clean up at this concentration of pollutants, even those that meet the standard of the $\mathrm{Pb}$ (II) set by the EPA of $0.005 \mathrm{mg} . \mathrm{L}^{-1}$ for drinking \& $0.05 \mathrm{mg} . \mathrm{L}^{-1}$ for waste water. The uptake capacity of metal ions $\&$ the adsorption mechanism involved depend on the surface charge of the adsorbent, the speciation of the adsorbate especially BET surface area $\&$ total pore volume (Hasan et al., 2008). Because the positively charged 
metal ions in a solution were adsorbed on the negative surface $\&$ thus the percentage removal of a metal ions increased with increasing BET surface area \& total pore volume (results are shown in Table 2). In the current experiments, the adsorption isotherm was very steep at this concentration, especially for all zeolites. This indicates that these samples can effectively remove $\mathrm{Pb}$ (II) from polluted environments, which is a property that is hardly achieved by the most of the available adsorbents.

Table 1. Maximum adsorption capacity for synthesized different type zeolites \& different sources

\begin{tabular}{|c|c|c|c|c|c|}
\hline $\begin{array}{l}\text { Sample } \\
\text { No. }\end{array}$ & $\begin{array}{l}\text { Sample } \\
\text { (Source) }\end{array}$ & $\begin{array}{l}\text { Qm } \\
\left(\mathrm{mg} \cdot \mathrm{g}^{-1}\right)\end{array}$ & Zeolite & $\begin{array}{l}\text { Qm } \\
\left(\mathrm{mg}^{-g^{-1}}\right)\end{array}$ & \%Adsorption \\
\hline 1 & Shale clay & 18.41 & (N1) & 97.73 & 97.73 \\
\hline 2 & Natural Montmorillonite & 11.22 & $(\mathrm{~N} 2)$ & 96.85 & 96.85 \\
\hline 3 & Barley husk & 5.10 & LTA & 95.09 & 95.09 \\
\hline 4 & Chert rock & 3.44 & (G3) & 94.16 & 94.16 \\
\hline 5 & & & (G2) & 93.12 & 93.12 \\
\hline 6 & & & (G1) & 90.87 & 90.87 \\
\hline
\end{tabular}

Table 2. $\mathrm{N}_{2}$ adsorption-desorption for synthesized different type zeolite from different sources

\begin{tabular}{llllll}
\hline Zeolites & $\begin{array}{l}\text { BET } \\
\text { surface area } \\
\left(\mathrm{m}^{2} \cdot \mathrm{g}^{-1}\right)\end{array}$ & $\operatorname{Pvb}\left(\mathrm{mL} \cdot \mathrm{g}^{-1}\right)$ & $\begin{array}{l}\text { Average crystal } \\
\text { size }(\mathrm{nm})-\mathrm{XRD}\end{array}$ & $\begin{array}{l}\text { Average } \\
\text { size }(\mathrm{nm})-\mathrm{TEM} \text {-Tal }\end{array}$ & $\begin{array}{l}\text { Average pore } \\
\text { size(nm) }\end{array}$ \\
\hline (N1) & 304.19 & 0.29 & 20.68 & 37.93 & 15.30 \\
(N2) & 288.07 & 0.45 & 19.52 & 50.00 & 21.49 \\
LTA & 284.31 & 0.29 & 21.32 & ------ & 22.04 \\
(G3) & 270.18 & 0.19 & 27.72 & 50.95 & 22.41 \\
(G2) & 262.04 & 0.24 & 28.88 & 24.66 & 25.11 \\
(G1) & 254.38 & 0.28 & 26.65 & 37.82 & 26.30 \\
\hline
\end{tabular}

${ }^{\mathrm{b}}$ Total pore volume obtained at $P / P_{0}=0.99$. *The crystal sizes were calculated by applying the Scherrer's equation to the XRD reflections of [060][551] [644] [624][ 551][733] planes for zeolite (1-6) respectively.

Table 3. $\mathrm{N}_{2}$ adsorption-desorption for different sources

\begin{tabular}{lll}
\hline Sources & $\begin{array}{l}\text { BET } \\
\text { surface area } \\
\left(\mathrm{m}^{2} \cdot \mathrm{g}^{-1}\right)\end{array}$ & $\mathrm{Pv}\left(\mathrm{mL} \cdot \mathrm{g}^{-1}\right)$ \\
\hline Shale clay & 61.87 & 0.1518 \\
Montmorillonite & 17.95 & 0.0449 \\
Barley husk & 11.99 & 0.0064 \\
Chert rock & 2.04 & 0.0073 \\
\hline
\end{tabular}

The samples were characterized using the N2 sorption to determine their surface area \& pore structure (Baerlocher et al., 2007).Figure 1(a-e) show the nitrogen adsorption/desorption isotherms \& their hysteresis N1, N2, LTA, G3, G2 \& G1 respectively, there are slight differences in the shapes of the adsorption isotherms of the different synthesized samples which are similar to the type IV adsorption isotherm, which suggests the presence of mesoporous in all samples., but they are different in their hysteresis according to the International Union of Pure \& Applied Chemistry (IUPAC) classification, (Sing, 1985).The BET surface area of N1, with one hysteresis loop at a relative pressure (0.4-0.99) H1-type with open-ended cylindrical pores with a uniform size \& shape, while N2, is H2- type hysteresis loop which associated with a capillary condensation in bottle pores shape, at a relative pressure (0.4-0.99). It was proven from the BJH pore size distributions in Figure 2 (a \& b) which exhibited one narrow peak at center ca. $15.30 \& 21.49 \mathrm{~nm}$ respectively. On the other hand the hysteresis loops of synthesized sample G3, G2, LTA \& G1 are H3-type hysteresis is usually seen on solids with a very wide distribution of pore size. The initial segment of the adsorption isotherm rises slowly with slight downwards concavity until the relative pressure is close to 0.99 , at which the point a quantity of nitrogen adsorption increases dramatically without demonstrating saturation phenomena. This means that capillary condensation occurs at high pressures, implying the presence of a mesoporous in the synthesized samples \& this could be 
related to the presence of slit-shaped pores (Alejandro et al., 2012; Chang et al., 2009; Tao et al., 2015; Sun et al., 2013) pore distribution are shown in Figure 2(c, d, e \& f) respectively). The BET surface area, the BJH average pore diameter $\&$ total pore volume for all these samples are reported in Table $2 \&$ for the source in Table 3. In contrast to the results for N1 to G1 samples the overall BET surface areas decreased dramatically \& the pore size was found to drop up to $26.30 \mathrm{~nm}$ (details given in Table 2). This could be due to a decrease in the pore size of the BET surface area $\&$ the increase in total pore volume.

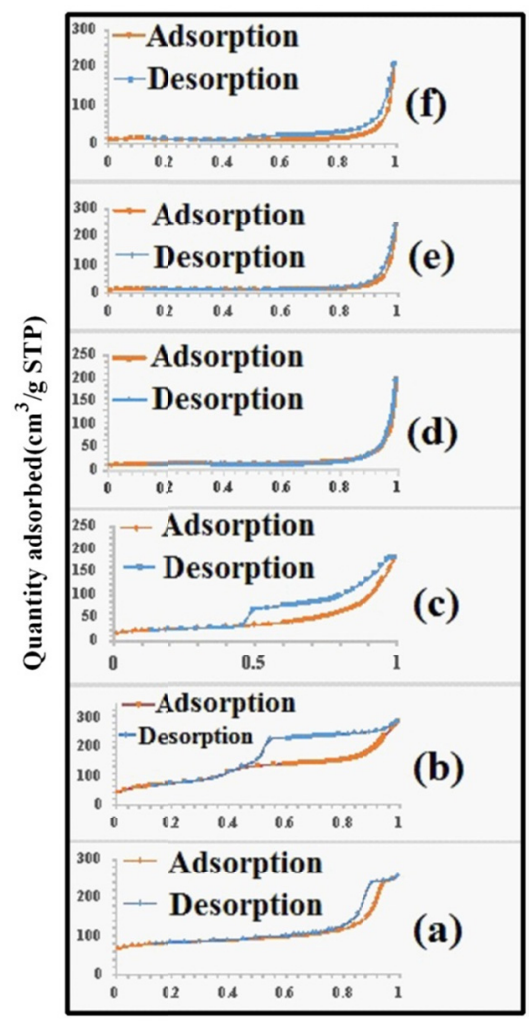

Relative pressure $\left(\mathbf{p} / \mathbf{p}^{\circ}\right)$

Figure 1. $\mathrm{N}_{2}$ adsorption-desorption isotherm $\mathrm{N} 1(\mathrm{a})$, N2(b), LTA(c), G3(d), G2(e) \& G1(f)

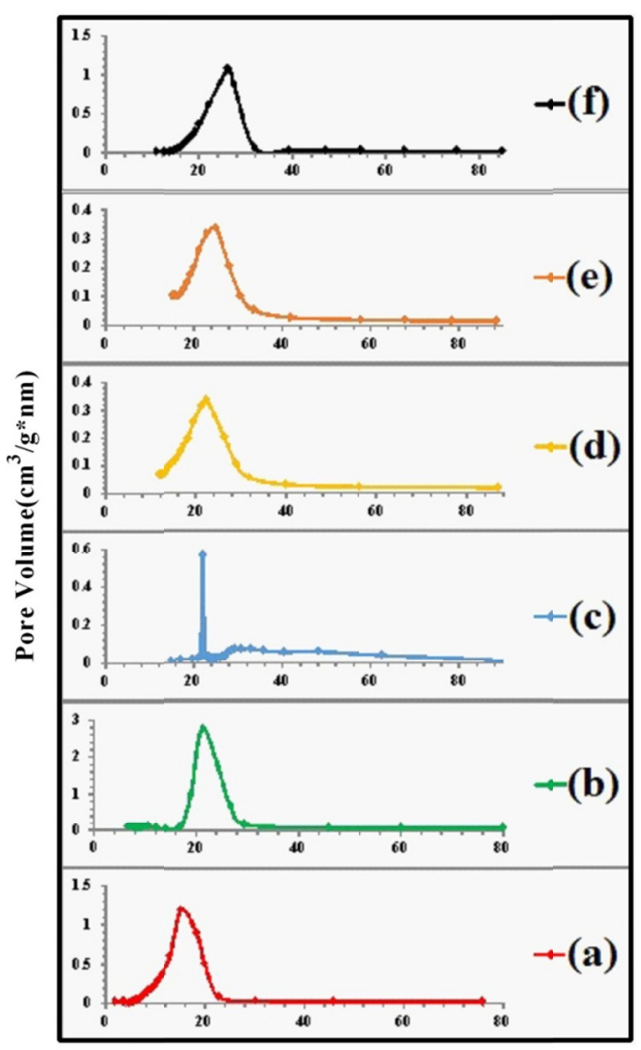

Pore Diameter $(\mathrm{nm})$

Figure 2. Pore size distribution N1(a), N2(b), LTA(c), G3(d), G2(e) \& G1(f)

\section{Conclusion}

The removal of heavy metals is an essential step in reducing the negative effects caused by their presence in non-target environments. The usage of low-cost sorbents such as zeolite can be considered as a viable option for the treatment of polluted water from heavy metals. In this study the utilization of the locally available low cost materials, predominantly silica-alumina sources to form different zeolites for removal of $\mathrm{Pb}$ (II) ions from aqueous solutions, synthesized zeolite proved to be substances that provide high adsorption of $\mathrm{Pb}$ (II). They can be used for removing heavy metals even at low levels of pollution. At the low initial concentration of $\mathrm{Pb}$ (II), modified N1 \& N2 zeolite from G3, LTA, G3, G2 \& G1 demonstrated to remove 97.73, 96.85, 95.09, 94.16, $93.12 \& 90.87 \%$ of the $\mathrm{Pb}$ (II) from the solution respectively.

\section{Acknowledgments}

The authors are thankful to the Salahaddin University in Kurdistan Regional Government for financial support.

\section{References}

Alejandro, D., Haro-Del, R., Aguilera-Alvarado, A. F., Cano-Aguilera, I., Martínez-Rosales, M., \& Holmes, S. (2012). Synthesis \& Characterization of Mesoporous Aluminosilicates for Copper Removal from Aqueous Medium. Materials Sciences \& Applications, 3, 485-491. https://doi.org/10.4236/msa.2012.37068

Baerlocher, C., McCusker, L. B., \& Olson, D. H. (2007). Atlas of Zeolite Framework Types, (6th Ed.) Elsevier. Breck, D. W. (1974). Zeolite Molecular Sieves, Structure, Chemistry, \& Use, Wiley-Interscience, New York. 
Chang, S. S., Clair, B., Ruelle, J., Beauchêne, J., Renzo, F., Quignard, F., Jie, G., Yamamoto, H., \& Gri, J. (2009). Mesoporosity as a new parameter for understanding tension stress generation in trees. Journal of Experimental Botany, 1-8. https://doi.org/10.1093/jxb/erp133

Chary, V. N. S., Kamala, C. T., \& Raj, D. S. S. (2008). Assessing risk of heavy metals from consumming food grown on sewage irrigated soils \& food chain transfer. Ecotox Environ Safe Journal, 69, 513-524. https://doi.org/10.1016/j.ecoenv.2007.04.013

Fujiwara, M., Sakamoto, A., Shiokawa, K., Patra, A. K., \& Bhaumik, A. (2011). Mesoporous MFI zeolite material from silica-alumina/epoxy-resin composite material \& its catalytic activity. Microporous and Mesoporous Materials, 142, 381-388. https://doi.org/10.1016/j.micromeso.2010.12.024

Gregg, S. J., \& Sing, K. S. W. (1982). Adsorption, surface area \& porosity, (2nd ed.). London, Academic press.

Hasan, S., Ghosh, T. K., Viswanath, D. S., \& Boddu, V. M. (2008). Dispersion of Chitosan on Perlite for Enhancement of Copper (II) Adsorption Capacity. Journal of Hazardous Materials, 152, 826-837. https://doi.org/10.1016/j.jhazmat.2007.07.078

Jaenicke, S., Chuah, G. K., Lin, X. H., \& Hu, X. C. (2000). Organic-inorganic hybrid catalysts for acid \& base-catalyzed reactions. Microporous and Mesoporous Materials, 35-36, 143-153. https://doi.org/10.1016/S1387-1811(99)00215-2

Katsuki, H., Furuta, Watari, S., T., \& Komarneni, S. (2005). ZSM-5 zeolite porous carbon composite conventional \& microwave-hydrothermal synthesis from carbonized rice husk. Microporous and Mesoporous Materials, 86, 145-151. https://doi.org/10.1016/j.micromeso.2005.07.010

Li, Z. J., Lew, C. M., Li, S. A., Medina, D. I., \& Yan, Y. S. (2005). Pure-Silica-Zeolite MEL Low - k Films from nanoparticle suspensions. Journal of physical chemistry B, 109(18), 8652-8658. https://doi.org/10.1021/jp0441893

Megat, M. A. K., Yahya, M. Z. A., Zakara, H., \& Ibrahim, S. C. (2007). An adsorption of Cd (II) ion from aqueos solution by lalang (imperata cylindrical) leaf powder effect of physicochemical environmental. Journal of Applied Sciences, 7(4), 489-493. https://doi.org/10.3923/jas.2007.489.493

Olaofe, O., Olagboye, S. A., Akanji, P. S., Adamolugbe, E. Y., Fowowe, O. T., \& Olaniyi, A. A. (2015). Kinetic studies of adsorption of heavy metals on clay. International Journal of Chemistry, 7, 48-54. https://doi.org/10.5539/ijc.v7n1p48

Potter, P. E., Maynard, J. B., \& Depetris, P. J. (2005). Mud \& Mudstones: Introduction \& Overview. Springer Verlag, Berlin.

Roulier, S., Kluge, B., Schmidt, S., Schulin, R., \& Wessolek, G. (2008). Accumulation \& transport of lead in roadside soils, Eurosoil.

Sing, K. S. W., Everett, D. H., Haul, R. A. W., Moscou, L., Pierotti, R. A., Rouquerol, J., \& Siemienewska, T. (1985). Reporting physisorption data for gas-solid systems. Pure Applied Chemistry, 57(4), 603-619. https://doi.org/10.1351/pac198557040603

Sitting, M. (1981). Hand book of toxic \& hazardous chemicals, Park Ridge, NJ, USA, Noyes Publications.

Soliman, A. M., Elwy, H. M., hiemann, T., Majedi, Y., Labata, F. T., \& Al-Rewashed, N. F. (2016). Removal of $\mathrm{Pb}$ (II) ions from aqueous solutions by sulphuric acid-treated palm tree leaves. Journal of the Taiwan Institute of Chemical Engineers, 58, 264-273. https://doi.org/10.1016/j.jtice.2015.05.035

Sun, J., Liu, H., Chen, X., Evans, D. G., \& Yang, W. (2013). An oil droplet template method for the synthesis of hierarchical structured $\mathrm{Co}_{3} \mathrm{O}_{4} / \mathrm{C}$ anodes for Li-ion batteries. Nanoscale, 5, 7564-7571. https://doi.org/10.1039/C3NR02385K

Tao, C. T., Guang, S. Z., Bo, W. S., \& Jia, X. (2015). A comparative study of the specific surface area \& pore structure of different shales \& their kerogens. Science China Earth Sciences, 58, 510-522. https://doi.org/10.1007/s11430-014-5021-2

\section{Copyrights}

Copyright for this article is retained by the author(s), with first publication rights granted to the journal.

This is an open-access article distributed under the terms and conditions of the Creative Commons Attribution license (http://creativecommons.org/licenses/by/4.0/). 